\title{
The dancing flea
}

What price perfection?

15 March 2015 The chairman stood beaming on the stage. "Any more questions? If not, let's thank the speaker... all right, one last question - please, go ahead."

The chairman pointed at a bulky man in the first row. The man stood up slowly, glanced around, and theatrically pointed a finger in the air. The handsome features of Karin Johanssen, the speaker who had just finished her talk, were distorted with impatience.

The man in the front row spoke, his words clipped by a distinctly east European accent. "But when the flea had shoes on, it could not dance any more," was all he said before he sat down again. The chairman paused for a moment, leaving the comment hanging in the air.

"If that's all, thanks to all the speakers who have presented such excellent advances in our mesophotonics session this morning. We'll have a coffee break and continue our session in 15 minutes." Karin stood perplexed for ten seconds and then forgot about the incident.

10 June 2015 Karin opened her hand-held and found a message she'd been expecting. "Dear Dr Johanssen, we are delighted to offer publication of your manuscript entitled 'Near-perfect light control in a photonic crystal optical cavity network' as an extended article. Thank you for choosing to publish your interesting work with us." She leaned back and smiled. This was only the beginning.

22 September 2015 Harold Dune walked into Karin's office, introduced himself and reassured his host that he had plenty of time this afternoon. Soon after Karin's most recent paper came out, Dune had posted a comment on the work, and offhandedly suggested an improvement for the layout of her device, adding that it was "just a thought”. It was, in fact, a very clever idea, which involved adding finer features to the optical cavity network.

Karin had already tried some of the fabrication steps needed for the improvement and was excited when she heard that Dune would be visiting the research centre. Now he was here, and within a few minutes they were drawing schemes and calculations on the flexiboard. After two hours of exchanging ideas, one last sketch remained. "It will take at least another year of work," Karin said, sounding far from disappointed.
12 June 2017 Karin entered the building, slowing her pace only to allow the terahertz security scanners to do their work. It had taken two years of meticulous work, but now she was ready to test the final version of her photonic chip, and she was feeling confident.

18 October 2017 The lab was buzzing quietly with electronic equipment. On the optical table stood the experiment they had been running for the past four weeks. Karin paced through the room, adjusted some instruments, and turned a light source off and on again. It's no use, she thought. A student came in and hesitated before putting down the apparatus he was carrying.

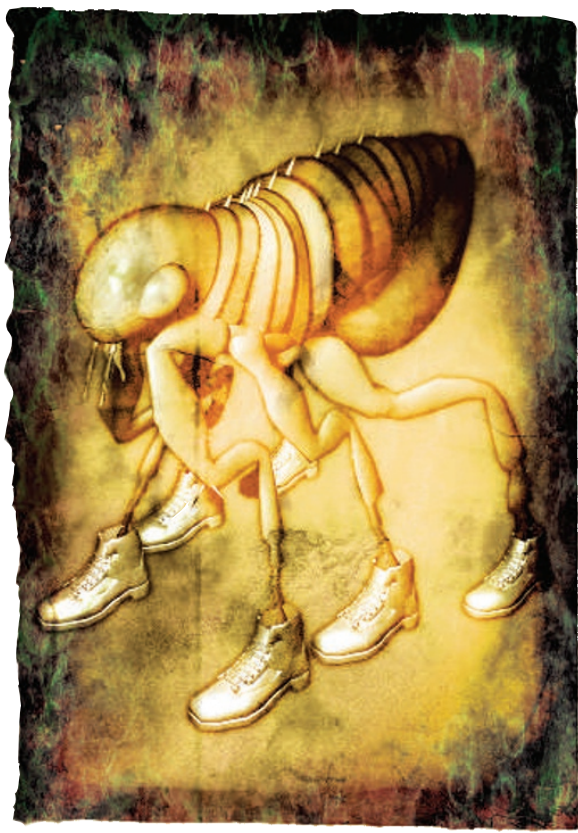

"Dr Johanssen, I found the amplifier you were looking for. Shall I start setting it up for you?"

His supervisor looked at him blankly and said, aloud this time: "It's no use."

5 November 2017 Karin sat alone in her office sipping the red wine she had saved as a reward for the end of her project. It was a mirthless celebration. Yes, she had succeeded in crafting a photonic chip that could control light perfectly, even better then she had boldly disingenuously - described in her research proposal all those years ago. But what was the point when all information that the light carried was irrevocably lost?
It was a perfect, useless device.

Almost certainly, there were some interesting, previously undiscovered dispersion mechanisms at work, worthy of study, and she could almost hear Harold trying to make her enthusiastic about it. She was not ready for that, not yet.

Her thoughts turned to Harold. She had wired him last night, and he had promised to come over to her lab immediately - no doubt interrupting his own work, although he would never admit it. How effortless, flawless their friendship had become. And that, curiously, troubled her too.

Harold found her in the dark emptiness of her office, deep in thought, with a glass of wine three-quarters full. "Karin," he said. "It's time to go. You have to let it go."

6 November 2017 Karin unrolled her laptop absentmindedly, logged on to web 3.5, barely knowing what she was looking for. When she had emerged from the lab yesterday, aware of Harold's reassuring presence at her side, a memory had slowly come back to her. After a dreamless night she had woken with an urgent realization that the memory was important. A conference two years back. Her first experimental results. This odd guy (Russian?) who stood up to make a cryptic, ridiculous remark. What was it that he had said, something about a dancing flea? She drew some words on the plastic screen - flea, dance. The search suggested some possible leads, neatly ordered in a diagram, but none seemed appropriate. What else could she add? She tried Russian.

This, presumably, was what she was meant to find. Taking a deep breath, Karin began reading the story, written by a oncefamous nineteenth-century Russian author.

"The tsar was impressed by the miniature clockwork toy that was made by English craftsmen, a dancing flea, and ordered his servants to find someone at home who could do better... The craftsman from Tula presented the tsar with what appeared to be the same minuscule flea. At first, the tsar was enraged but, after some encouraging, took a closer look, closer still and finally noticed that it has been given an even finer feature; miniature metallic shoes. Only, now that it was perfect, it could not dance any more."

\section{Liesbeth Venema \\ Liesbeth Venema is a senior editor for the physical sciences at Nature.}

